\title{
EVALUASI PENERAPAN STANDAR OPERASIONAL PROSEDUR KARYAWAN PANEN TERHADAP KUALITAS DAN KUANTITAS PANEN TANDAN BUAH SEGAR KELAPA SAWIT (Elaels guineensis jacq) SERTA HANCAK PANEN (Studi Kasus: PT. Sentosa Kalimantan Jaya)
}

\section{EVALUATION OF HARVEST EMPLOYEE OPERATIONAL STANDARD APPLICATION ON HARVEST QUALITY AND QUANTITY MARKET FRESH PALM OIL (Elaels guineensis jacq) AND HARVEST DESTRUCTION (Case Study: PT. Sentosa Kalimantan Jaya)}

\author{
Lydia Apria Rosadi*1, Rusli Anwar ${ }^{1}$, Rusmini ${ }^{1}$ \\ ${ }^{1}$ Politeknik Pertanian Negeri Samarinda, Kampus Gunung Panjang, Jl. \\ Samratulangi, Samarinda, Indonesia \\ lydiaapriarosadi14@gmail.com
}

\begin{abstract}
This research is motivated by the number of oil palm companies that require employees to do work according to standards companies such as harvest employees who must harvest according to quality ripe fruit and harvest ripe reach the company's target, but in the statement the harvest work does not pay attention to operational standards procedures (SOP) that have been made and implemented in the company, so it is necessary carried out observations of the application of standard operating procedures for employees to harvest fresh fruit bunches (FFB). The objectives of this research are to identify the characteristics of respondents based on age, sex, work experience, education in general and to monitor the implementation of standard operating procedures for harvest employees on the quality and quantity of harvested fresh oil palm fruit bunches and harvest rights. Collecting data related to the implementation of harvest employee SOPs was obtained through the observation method, the interview method, and the documentation method. To analyze this data, data analysis was used in this study collected from research sources using descriptive analysis methods and Likert scale.
\end{abstract}

Keywords: Evaluation, SOP Application, Harvest Employees

\section{PENDAHULUAN}

Karyawan yang berhubungan secara langsung dengan produk yang dihasilkan perkebunan adalah karyawan panen sebagai pemanen dari kelapa sawit yang dihasilkan. Karyawan bukan semata obyek dalam pencapaian tujuan perusahaan, tetapi juga menjadi subyek atau pelaku, selain itu karyawan dapat menjadi perencana dan pelaksanaan yang berperan aktif dalam mewujudkan tujuan organisasi perusahaan serta mempunyai pikiran, perasaan, dan keinginan yang dapat mempengaruhi sikapnya dalam melakukan perkejaan.

perusahaan kelapa sawit karyawan di wajibkan mengerjakan pekerjaan panen sesuai dengan standar perusahaan.

Evaluasi panen sangat dibutuhkan dalam kegiatan pemanen, kegiatan panen yang baik disertai dengan evaluasi terhadap mutu panen. Evaluasi mutu panen dilakukan untuk 
memperhitungkan potensi kehilangan hasil dan mencegah terjadinya kehilangan hasil, evaluasi terhadap mutu panen terdiri dari evaluasi mutu buah maupun mutu hancak.

Dengan adanya SOP semua
kegiatan perusahaan dapat
terancang dengan baik dan dapat
berjalan sesuai dengan kemauan
perusahaan. SOP dapat

didefiniskan sebagai dokumen yang menjabarkan aktivitas operasional yang dilakukan sehari-hari, dengan tujuan agar pekerjaan tersebut dilakukan secara benar, tepat, dan konsisten untuk menghasilkanproduk sesuai standar yang telah ditetapkan sebelumnya (Tathagati, 2014).

Penelitian dilakukan pada tingkat afdeling di PT. Sentosa Kalimantan Jaya, objek yang menjadi penelitian ini ialah SOP karyawan panen yang melakukan pelaksanaan terhadap kegiatan panen. Selain itu, kualitas dan kuantitas TBS serta hancak panen menjadi pendukung untuk melihat SOP karyawan panen yang telah diterapkan di perusahaan.

\section{METODOLOGI}

Adapun sumber data dalam penelitian ini adalah subyek dari mana data dapat diperoleh. Dalam penelitian ini penulis menggunakan data primer dan data sekunder. Adapun data terkait dengan sop penerapan karyawan panen kuantitas dan kualitas TBS dan hancak panen metode yang digunakan adalah metode audit, metode interview, metode dokumentasi. Metode audit yaitu langkah-langkah yang dilakukan oleh peneliti untuk mendapatkan semua informasi mengenai kualitas dan kuantitas serta hancak panen yang disediakan oleh perusahaan, metode interview yaitu dialog yang pewawancara untuk memperoleh informasi, metode dokumentasi adalah cara suatu cara yang dugunakan untuk memperoleh data dan informasi dalam bentuk buku, arsip, dokumen, tulisan angka dan gambar berupa laporan serta keterangan yang dapat mendukung penelitian.adapun langkah selanjutnya yang dapat dilakukan yaitu melakukan survey lokasi yang bertujuan untuk melihat dan menetukan tempat afdelling yang akan dilakukan untuk memperoleh sop karyawan panen, kualitas dan kuantitas, serta hancak panen.

Skala likert adalah suatu skala yang umum digunakan dalam kuesioner dan merupakan skala yang paling banyak digunakan dalam riset berupa survei.Pada penelitian ini penulis menggunakan metode skala likert, skala likert digunakan untuk mengukur sikap, pendapat, dan persepsi seseorang atau sekelompok orang (Sugiyono, 2009). Pilihan terhadap masingmasing jawaban-jawaban responden dapat diberi bobot nilai atau skor likert sebagai berikut bobot nilai 5 sangat tinggi,bobot nilai 4 tinggi,bobot nilai 3 sedang,bobot nilai 2 rendah,bobot nilai 1 sangat rendah.

Jumlah skor observasi adalah jumlah dari skor masingmasing butir pernyataan hasil observasi yang dikalikan dengan bobot skor menurut skala likert. Untuk mendapatkan hasil responden harus diketahui terlebih dahulu jarak interval masing-masing dari pernyataan yaitu dengan mengetahui skor maksimal, skor maksimal yang dimaksud adalah skor maksimal skala likert yang dikalikan dengan jumlah butir soal pernyataan, sehingga $5 \times 13=65$. Jumlah skor yang diharapkan 
adalah skor maksimal yang dikalikan dengan jumlah responden, sehingga $5 \times 65=325$.

Persentase Penerapan sop

$=\frac{\text { Skor observasi }}{\text { Skor yang diharapkan }} \times 100$

Berikut kriteria presentasei skor observasi sebagai berikut:

Indeks 0\% - 19,99\% : Sangat Rendah

Indeks 20\% - 39,99\% : Rendah

Indeks 40\% - 59,99\% : Sedang

Indeks 60\% - 79,99\% : Tinggi

Indeks $80 \%-100 \% \quad$ : Sangat

Tinggi

\section{HASIL DAN PEMBAHASAN}

Dalam penelitian ini karakteristik responden merupakan aspek yang juga digali secara mendalam, karena karakteristik responden sangat menentukan kemampuan kerja karyawan dalam tugasnya sebagai pemanen. Karakteristik responden dikelompokkan dalam kategori berdasarkan usia, jenis kelamin, tingkat pendidikan dan pengalaman kerja.

Tabel. Karakteristik Responden Afdeling IV dan V

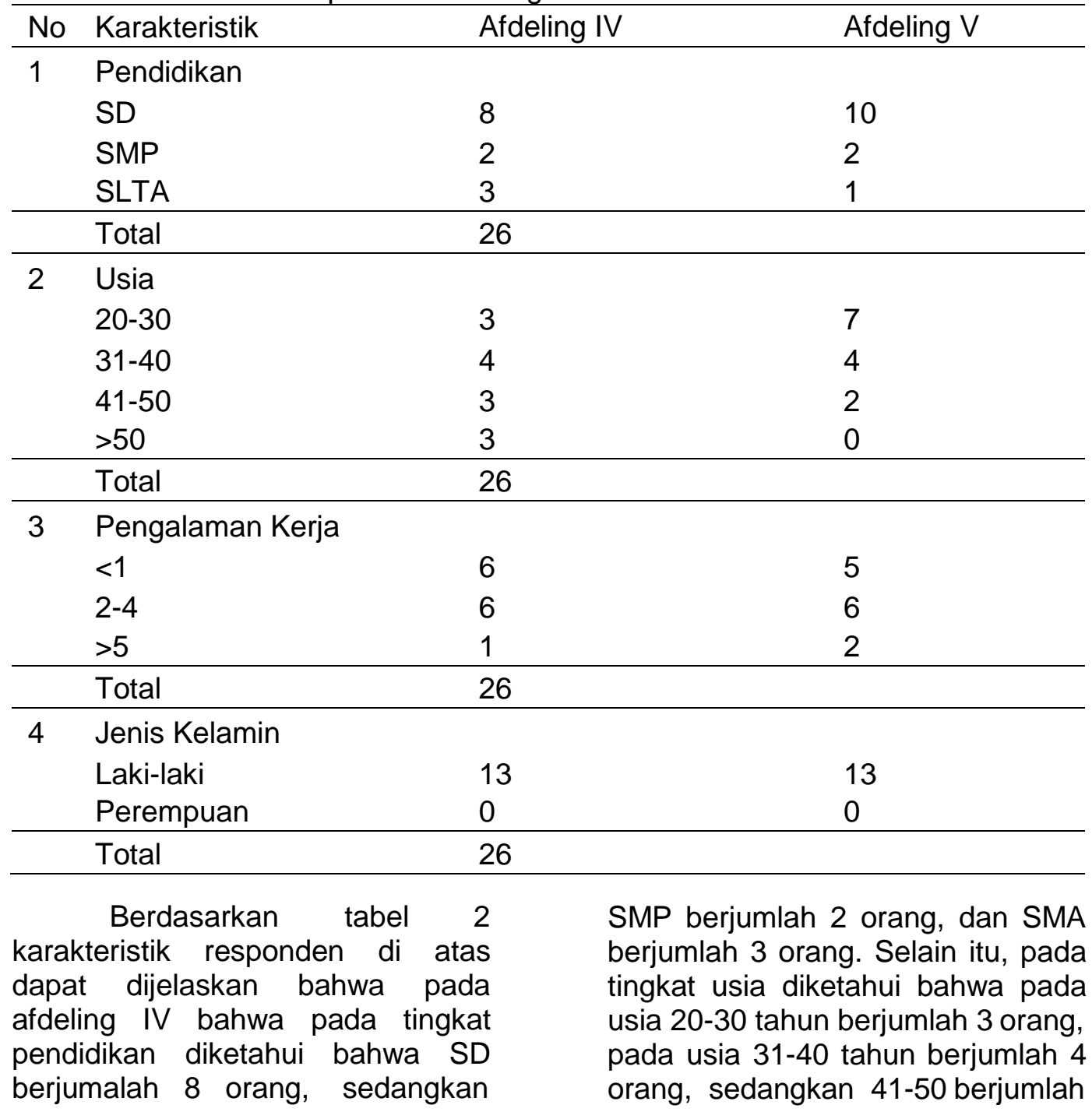


3 orang dan $>50$ berjumlah 3 orang. Pada tingkat pengalaman kerja diketahui bahwa $<1$ tahun kerja berjumlah 6 orang, pengalaman kerja 2-4 tahun berjumlah 6 orang, sedangkan pada pengalaman kerja $>5$ tahun berjumlah 1 orang. Adapun pada tingkat jenis kelamin diketahui bahwa jenis kelamin laki-laki berjumlah 13 orang sedangkan jenis kelamin perempuan 0 . Karakteristik responden pada afdeling $\mathrm{V}$ dapat dijelaskan bahwa pada tingkat pendidikan diketahui bahwa SD berjumlah 10 orang, sedangkan SMP berjumlah 2 orng dan pada tingkat SMA berjumlah 1 orang. Selain itu, pada tingkat usia diketahui bahwa pada usia 20-30 tahun berjumlah 7 orang, pada usia 31-40 tahun berjumlah 4 orang, sedangkan pada usia 41-50 berjumlah 2 orang dan $>50$ tidak ada. Pada tingkat pengalaman kerja diketahui bahwa $<1$ tahun berjumlah 1 orang, pengalaman kerja 2-4 tahun berjumlah 6 orang, sedangkan pengalaman kerja $>5$ tahun berjumlah 2 orang. Adapun pada tingkat jenis kelamin diketahui bahwa jenis kelamin laki-laki berjumlah 13 orang sedangkan jenis kelamin perempuan 0 .

\section{Nilai Penerapan SOP}

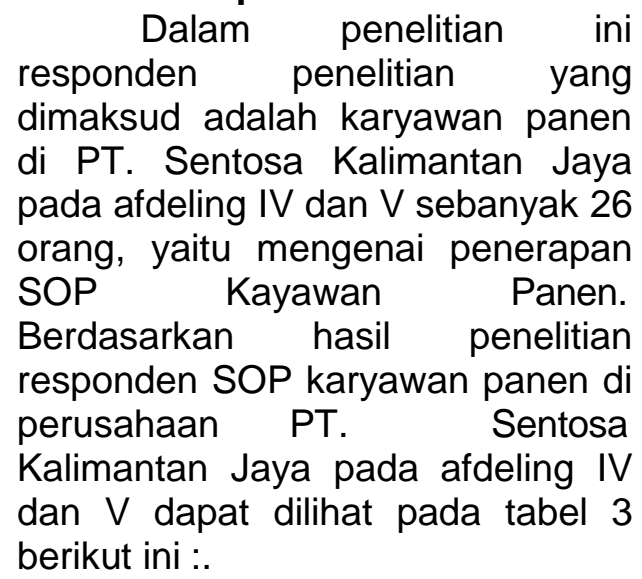

Tabel 3. Nilai penerapan SOP Karyawan Panen Afdeling IV

\begin{tabular}{|c|c|c|c|}
\hline \multicolumn{4}{|c|}{ Hasil Nilai 13 Responden } \\
\hline \multirow{2}{*}{$\begin{array}{l}\text { Pernyataan } \\
1\end{array}$} & Skor Nilai & Persentase \% & Kategori \\
\hline & 57,53 & $57,53 \%$ & Sedang \\
\hline 2 & 80,00 & $80,00 \%$ & Sangat Tinggi \\
\hline 3 & 79,69 & $79,69 \%$ & Tinggi \\
\hline 4 & 44,92 & $44,92 \%$ & Sedang \\
\hline 5 & 41,53 & $41,53 \%$ & Sedang \\
\hline 6 & 45,53 & $45,53 \%$ & Sedang \\
\hline 7 & 59,38 & $59,38 \%$ & Sedang \\
\hline 8 & 79,69 & $79,69 \%$ & Tinggi \\
\hline 9 & 69,53 & $69,53 \%$ & Tinggi \\
\hline 10 & 56,92 & $56,92 \%$ & Sedang \\
\hline Rata-Rata & 61,472 & $61,47 \%$ & Tinggi \\
\hline \multicolumn{2}{|c|}{$\begin{array}{l}\text { Dari hasil tabel } 3 \text { di ata } \\
\text { diketahui bahwa jumlah dari has } \\
\text { quisioner terhadap } 13 \text { responder } \\
\text { afdeling IV adalah } 61,472 \text { sert } \\
\text { rata-rata skor nilai dari penerapar } \\
\text { SOP panen karyawan adalah } 61,47\end{array}$} & \multicolumn{2}{|c|}{$\begin{array}{c}\text { dan rata-rata dari persentase } \\
\text { adalah } 61,47 \% \text {. } \\
\text { Jadi, dalam perhitungan } \\
\text { rata-rata skor diperoleh nilai } 61,47 \\
\text { serta presentasenya adalah } 61,47 \% \\
\text { yang berarti masuk dalam kategor } \\
\text { "Tinggi" (dapat dilihat pada tabel }\end{array}$} \\
\hline
\end{tabular}


hasil skor nilai pembobotan tabel 3). Berdasarkan hasil penelitian responden SOP karyawan panen di perusahaan PT. Sentosa Kalimantan Jaya dapat dilihat pada tabel 4 berikut ini.

Tabel 4. Nilai penerapan SOP karyawan panen Afdeling V

\begin{tabular}{llll}
\hline & Hasil Nilai 13 Responden & \\
\hline Pernyataan & Skor Nilai & Persentase\% & Kategori \\
1 & 37,23 & $37,27 \%$ & Rendah \\
\hline 2 & 80,00 & $80,00 \%$ & Sangat Tinggi \\
3 & 40,92 & $40,92 \%$ & Sedang \\
4 & 80,00 & $80,00 \%$ & Sangat Tinggi \\
5 & 61,53 & $61,53 \%$ & Tinggi \\
6 & 57,53 & $57,53 \%$ & Sedang \\
7 & 64,92 & $64,92 \%$ & Tinggi \\
8 & 80,00 & $80,00 \%$ & Sangat Tinggi \\
9 & 72,61 & $72,61 \%$ & Tinggi \\
10 & 23,69 & $23,69 \%$ & Rendah \\
\hline Rata-Rata & 59,843 & $59,85 \%$ & Sedang \\
\hline
\end{tabular}

Dari hasil tabel di atas diketahui bahwa jumlah dari 13 responden afdeling $V$ adalah 59,843 serta hasil dari rata-rata 13 responden adalah 59,843 dan ratarata dari perhitungan presentase afdeling $\mathrm{V}$ adalah $59,85 \%$. Jadi, perhitungan dari ratarata skor adeling $\mathrm{V}$ adalah 59,843 serta presentase dari afdeling $\mathrm{V}$ adalah $59,85 \%$ yang berarti masuk dalam kategori "SEDANG" (dapat dilihat pada tabel 4). Berdasarkan hasil penelitian di lahan perusahaan PT. Sentosa Kalimantan Jaya hasil prestasi hasil panen di afdeling IV dapat dilihat pada tabel 5 berikut :

Tabel 5. Hasil Prestasi Panen Afdeling IV

\begin{tabular}{lcccc}
\hline & \multirow{2}{*}{ No Ancak } & \multirow{2}{*}{ Basis } & Jumlah & \multicolumn{2}{c}{ Basis Janjang } \\
\cline { 5 - 6 } & & Janjang & Lebih & Kurang \\
\hline Jumlah & - & 12.836 & 3.424 & 0 \\
Rata-Rata & 181 & 987 & 263 & 0 \\
\hline Hasil prestasi panen afdeling $\mathrm{V}$ & & & & \\
\hline Jumlah & - & 9.728 & 3.201 & 493 \\
Rata-Rata & 135 & 748 & 246 & 38 \\
\hline
\end{tabular}

Berdasarkan tabel 5 di atas diketahui bahwa hasil penen karyawan afdeling IV dapat dijelaskan bahwa seluruh karyawan bisa mencapai target/basis panen yang diterapkan perusahaan yaitu 181 janjang/hk. Rata-rata jumlah luas lahan yang di panen di afdeling IV adalah 10ha, sedangkan rata- rata BJR di afdeling IV adalah $8 \mathrm{~kg}$, rata-rata jumlah janjang yang diperoleh karyawan di afdeling IV adalah 987 janjang, rata-rata jumlah lebih basis janjang di afdeling IV adalah 263 janjang, dan jumlah rata-rata kurang basis karyawan panen di afdeling IV adalah 0 . Berikut ini adalah prestasi panen 
karyawan di afdeling $\mathrm{V}$ di lahan perusahaan PT. Sentosa Kalimantan Jaya yang dapat dilihat pada tabel 5 .

Berdasarkan pada tabel di atas dinyatakan bahwa hasil penelitian jumlah prestasi panen di afdeling V. Rata-rata jumlah luas lahan afdeling $\mathrm{V}$ adalah 10ha, sedangkan standar janjang dari afdeling $V$ adalah $135 / \mathrm{hk}$, rata-rata BJR di afdeling $\vee 15 \mathrm{~kg}$, rata-rata jumlah janjang yang didapatkan oleh karyawan afdeling $\mathrm{V}$ adalah 748 janjang, selain itu rata-rata lebih basis yang didapatkan oleh karyawan panen afdeling $\mathrm{V}$ adalah 246 janjang, namun masih ada beberapa karyawan yang belum mencapai rata-rata dari standar perusahaan yaitu 38 janjang dari rata-rata yang didapat. Mutu hancak panen dapat dilihat pada tabel 6 berikut ini :.

Tabel 6. Mutu Ancak Afdelling IV

\begin{tabular}{|c|c|c|c|c|c|c|c|}
\hline \multirow[b]{2}{*}{$\begin{array}{l}\text { No } \\
\text { Ancak }\end{array}$} & \multicolumn{7}{|c|}{ Kriteria } \\
\hline & $\begin{array}{l}\text { Buah } \\
\text { Tinggal }\end{array}$ & $\begin{array}{l}\text { Brondolan } \\
\text { Tinggal }\end{array}$ & $\begin{array}{l}\text { Buah } \\
\text { Matahari }\end{array}$ & $\begin{array}{l}\text { Pelepah } \\
\text { Sengkleh }\end{array}$ & $\begin{array}{l}\text { Pelepah } \\
\text { Tidak } \\
\text { Disusun }\end{array}$ & $\begin{array}{l}\text { Under } \\
\text { Prunning }\end{array}$ & $\begin{array}{l}\text { Over } \\
\text { Prunning }\end{array}$ \\
\hline Total & 354 & 13.703 & 271 & 83,00 & 4.573 & 2.460 & 4.746 \\
\hline $\begin{array}{l}\text { Rata- } \\
\text { Rata }\end{array}$ & 27,23 & 1.054 & 20,85 & 6,38 & 351,76 & 189,23 & 365,07 \\
\hline \multicolumn{8}{|c|}{ Tabel 7. Mutu Ancak AfdelingV } \\
\hline \multirow[b]{2}{*}{$\begin{array}{l}\text { No } \\
\text { Ancak }\end{array}$} & Kriteria & & & & & & \\
\hline & $\begin{array}{l}\text { Buah } \\
\text { Tinggal }\end{array}$ & $\begin{array}{l}\text { Brondolan } \\
\text { Tinggal }\end{array}$ & $\begin{array}{l}\text { Buah } \\
\text { Matahari }\end{array}$ & $\begin{array}{l}\text { Pelepah } \\
\text { Sengkleh }\end{array}$ & $\begin{array}{l}\text { Pelepah } \\
\text { Tidak } \\
\text { Disusun }\end{array}$ & $\begin{array}{l}\text { Under } \\
\text { Prunning }\end{array}$ & $\begin{array}{l}\text { Over } \\
\text { Prunning }\end{array}$ \\
\hline Total & 135 & 3.171 & 73 & 74 & 1.384 & 3.213 & 3.139 \\
\hline $\begin{array}{l}\text { Rata- } \\
\text { Rata }\end{array}$ & 10,38 & 243,92 & 5,61 & 5,69 & 106,46 & 247,15 & 241,46 \\
\hline
\end{tabular}

Berdasarkan tabel di atas dapat dinyatakan bahwa hasil dari rata-rata mutu hancak pada afdeling IV, rata-rata buah tinggal di afdeling IV adalah 27,23 sedangkan brondolan yang tinggal rata-ratanya adalah 1054, rata-rata buah matahari yang ada dipokok adalah 20,85 , rata-rata pelepah sengkleh yang ada di pokok adalah 6,38, selain itu rata-rata dari pelepah yang tidak tersusun rapi di sekitar pokok kelapa sawit 3571,36 pelepah, rata-rata over pruning yang terjadi pada afdeling IV adalah 189,23, dan rata-rata under prunning yang terjadi pada afdeling IV adalah 365,07.
Dari data hasil mutu hancak pada afdeling $\mathrm{V}$ di atas merupakan hasil dari rata-rata mutu hancak. Rata-rata dari buah tinggal adalah 10,38 , sedangkan brondol yan tertinggal di pokok, piringan, gawangan rata-ratanya adalah 243,92 , rata-rata buah matahari yang tinggal dipohon adalah 5,61, rata-rata pelepah sengkleh yang ada dipohon adalah 5,69, pelepah yang tidak disusun disekitar piringan rata-ratanya adalah 106,46, sedangkan pelepah under prunning rata-ratanya adalah 247,15 dan ver prunning rataratanya adalah 241,46 . 
Hasil rata-rata dari pengamatan mutu buah TBS kelapa sawit perusahaan pada afdelling IV dan V dapat dilihat pada tabel 8 dan 9 berikut ini.

Tabel 8. Mutu Buah Afdelling IV

\begin{tabular}{lllllll}
\hline \multirow{2}{*}{ No } & Nama & Buah & Buah & Buah & Tangkai & Lewat \\
& Pemanen & normal & mentah & Busuk & Panjang & Masak \\
\hline Total & & 9.258 & 0 & 179 & 38 & 570 \\
Rata-Rata & & 712,15 & 0 & 13,76 & 2,92 & 43,84 \\
\hline
\end{tabular}

Tabel 9. Mutu Buah Afdelling V

\begin{tabular}{lllllll}
\hline \multirow{2}{*}{ No } & Nama & Buah & Buah & Buah & Tangkai & Lewat \\
& Pemanen & normal & mentah & Busuk & Panjang & Masak \\
\hline Total & & 4.054 & 18 & 0 & 45 & 62 \\
Rata-Rata & & 311,84 & 1,38 & 0 & 3,46 & 4,76 \\
\hline
\end{tabular}

Berdasarkan tabel 8 dan 9 di atas mutu buah di afdeling IV dan V . Rata-rata buah normal yang ada di afdelling IV adalah 712,15, sedangkan buah mentah yang ada di afdelling 0 (Tidak ada), rata-rata buah adalah 13,76, rata-rata tangkai panjang yang ada di afdelling IV adalah 2,92, dan buah yang lewat masak rata-ratanya adalah 43,84.

Berdasarkan hasil rata-rata mutu buah dapat dinyatakan bahwa, buah normal yang berada di afdelling $\mathrm{V}$ adalah 311,84 buah, sedangkan buah mentah rataratanya adalah 1,38 buah, buah busuk yang berada di afdelling $\mathrm{V} 0$ (tidak ada), selain itu tangkai panjang yang ditemukan di afdelling $\checkmark$ rata-ratanya adalah 3,46 tangkai panjang dan buah yang lewat masak rata-ratanya adalah 4,76.

Berdasarkan hasil evaluasi penilaian SOP karyawan panen pada tingkat afdeling IV dan Afdeling $\mathrm{V}$ dapat dijelaskan bahwa capaian penerapan SOP pada afdeling IV dengan skor nilai 61,472 dengan persentase $61,47 \%$ kategori "Tinggi" dan pada afdeling $\mathrm{V}$ dengan capain skor nilai 59,843 dengan persentase 59,85\% kategori "Sedang".
Menurut Hasibuan (2006), menyatakan adanya pengaruh deskripsi kerja terhadap pekerjaan, yakni apabila deskripsi kerja kurang jelas akan mengakibatkan seseorang karyawan kurang mengetahui tugas dan kurang tanggung jawabnya pada pekerjaan itu, mengakibatkan pekerjaan tidak tercapai dengan baik. Dengan adanya perancangan pekerjaan dan deskripsi tugas yang jelas, maka akan semakin produktif dan berprestasi sehingga keuntungan ekonomis dari deskripsi pekerjaan akan diperoleh.

Hal yang mempengaruhi tingginya pelaksanaan SOP pada tingkat afdeling IV berdasarkan hasil wawancara dan observasi langsung adalah :

a. Mandor mampu memberikan contoh perilaku yang baik, agar dapat dijadikan contoh bagi seluruh karyawan panen yang dapat dilihat pada lampiran gambar 1

b. Pengawasan yang ketat yang dilakukan oleh mandor panen, seperti melakukan pengecekan keliling pada setiap hancak yang di panen oleh karyawan panen yang dapat dilihat pada lampitan gambar 2 . 
c. Memberikan arahan serta pemahaman apel pagi yang dapat dilihat pada, kepada karyawan SOP agar tidak tejadi pelanggaran SOP seperti tidak menngunakan APD lampiran gambar 3

Menurut Siahaan dan Erningpraja (2005), untuk menjamin perolehan TBS yang berkualitas, pengawasan mutu panen perlu dilakukan secara intensif dan reguler. Pengawasan tersebut antara lain rotasi panen dan pemanenan TBS pada tingkat kematangan optimal. Penanggulangan yang baik dalam mutu buah yaitu dengan pengawasan yang sesering mungkin di TPH dan hancak panen (Pahan, 2008)

Hal yang mempengaruhi kurangnya penerapan SOP karyawan panen afdeling $\mathrm{V}$ berdasarkan hasil wawancara dan observasi langsung adalah kurangnya tingkat pengawasan yang dilakukan oleh mandor, selain itu karyawan panen pada afdeling $\mathrm{V}$ kurang kesadaran diri untuk merapkan SOP panen seperti kurangnya memperhatikan prestasi panen.

\section{KESIMPULAN}

Berdasarkan hasil penelitian mengenai evaluasi penerapan SOP karyawan panen terhadap kualitas dan kuantitas tandan buah segar kelapa sawit (Elaeis gueneensis Jacq.) serta hancak panen di PT. SKJ, Maka dapat ditarik kesimpulan sebagai berikut :

1. Pencapaian penerapan nilai SOP karyawan panen per afdeling yang tinggi adalah afdeling 4 dengan skor nilai 61,472 dan persentase $61,47 \%$ (Tinggi),sedangkan nilai yang sedang adalah afdeling $\mathrm{V}$ dengan skor nilai 59,843 dan persentase

$59,85 \% \quad$ (Sedang) jika mengacu pada lima kategori skala likert.

2. Karakteristik responden termasuk faktor yang berpengaruh terhadap keberhasilan penerapan SOP karyawan panen terutama usia, pengalaman kerja, dan jenis kelamin, bentuk pengaruhnya kemampuan dalam memenuhi pengawasan teknik dalam memanen TBS.

3. Penerapan SOP karyawan panen di PT. Sentosa Kalimantan Jaya belum sepenuhnya diterapkan oleh pihak karyawan panen dan dapat dilihat bahwa afdeling IV lebih unggul dari segi kualitas sedangkan dari segi kuantitas afdeling $\mathrm{V}$ lebih unggul.

\section{DAFTAR PUSTAKA}

Tathagati,A. (2014). Step by step membuat SOP. Jakarta: Efata Publishing.

Sugiyono, 2009. Metode Penelitian Kuantitatif Kualitatif dan R\&D.Bandung: Alfabeta

Hasibuan, Malayu S.P, 2006, Manajemen

Dasar,Pengertian, dan Masalah , Edisi Revisi, Bumi Aksara: Jakarta

Siahaan, D., Erningpraja, L. 2005. Penerapan Good Agriculture Practice dan Good Manufacture Practice dalam Meningkatkan Mutu dan Keamanan Pangan Minyak Kelapa Sawit. J Penelitia Kelapa Sawit. Vol. 13, No. 3:109-118

Pahan, I. 2008. Kelapa Sawit: Manajemen Agribisnis dari 
Hulu hingga Hilir. Penebar

Swadaya. Jakarta. 